\title{
Broadcast of Surgical Procedures as a Teaching Instrument in Cardiothoracic Surgery
}

\author{
Robert M. Sade, MD, for the American Association for Thoracic Surgery Ethics Committee and The Society of Thoracic \\ Surgeons Standards and Ethics Committee*
}

From the American Association for Thoracic Surgery, Beverly, Massachusetts; and The Society of Thoracic Surgeons, Chicago, Illinois.

This article is being published simultaneously in The Annals of Thoracic Surgery and The Journal of Thoracic and Cardiovascular Surgery.

* American Association for Thoracic Surgery Ethics Committee-Drs Robert M Sade, Charleston, South Carolina (Chair); Cary W. Akins, Boston, Massachusetts; Joseph J. Amato, Chicago, Illinois; James W. Jones, Houston, Texas, and Andrew S Wechsler, Philadelphia, Pennsylvania; and The Society of Thoracic Surgeons Standards and Ethics Committee-Drs Robert $\mathrm{M}$. Sade, Charleston, South Carolina (Chair); Mark S. Allen, Rochester, Minnesota; David N. Campbell, Aurora, Colorado; Richard M. Engelman, Springfield, Massachusetts; Mark K. Ferguson, Chicago, Illinois; Steven W. Guyton, Seattle, Washington; John W. Hammon Jr, Winston-Salem, North Carolina; Sidney Levitsky, Boston, Massachusetts; John E. Mayer Jr, Boston, Massachusetts; Eric N. Mendeloff, Dallas, Texas; Mark B. Orringer, Ann Arbor, Michigan; Ross M. Ungerleider, Portland, Oregon; Donald C. Watson, Biltmore Forest, North Carolina; and Walter G. Wolfe, Durham, North Carolina.

Address correspondence to Dr Sade, Institute of Human Values in Health Care, Division of Cardiothoracic Surgery, Department of Surgery, Medical University of South Carolina, 96 Jonathan Lucas St, Ste 409, Charleston, SC 29425 (E-mail: sader@ musc.edu)

J Thorac Cardiovasc Surg 2008;136:273-7 $0022-5223 / \$ 34.00$

Copyright $(2008$ by The American Association for Thoracic Surgery

doi:10.1016/j.jtcvs.2008.06.015
$\mathrm{P}$ hysicians have had an obligation to teach their art to others at least since the time of Hippocrates. Instruction during live operations has been in widespread use at least since the 19th century. Until recently, such intraoperative instruction was necessarily a local event, with teacher and pupil standing over the open surgical wound. In the latter part of the 20th century, transmission of images electronically over long distances became possible, and broadcasts of cardiothoracic operations in real time have become popular in recent years worldwide, especially in Europe.

As the use of these technologies has increased, the intensity of controversy surrounding them has grown in parallel. The disagreement has centered on questions of potential or real harm to patients related to broadcasts of operations and the ill-defined value of such broadcasts. Several national surgical associations have banned the practice from some or all of their meetings, including the American College of Obstetricians and Gynecologists and the American College of Surgeons (M. McGrath, personal communication, February 9, 2006).

Out of concern for patient safety, several Japanese cardiac, thoracic, and vascular surgery societies created a Joint Committee to examine the controversy, and on August 10, 2007, the Joint Committee issued guidelines for regulating live surgery broadcasts at their meetings. ${ }^{1}$ Their report is being considered for adoption by other surgical associations worldwide and has been carefully considered by both the American Association for Thoracic Surgery (AATS) and The Society of Thoracic Surgeons (STS).

The STS asked its Standards and Ethics Committee to examine this issue, and the committee recommended that the Japanese guidelines not be adopted, that public live surgery broadcasts not be permitted, and that such broadcasts not be permitted at its annual meeting. In response, The STS Board of Directors appointed a task force, under the leadership of Dr Sidney Levitsky, to examine this issue in depth. The task force's recommendations were adopted, and The STS Guidelines for Ethical Relations With Communications Media were revised to strengthen Section IV and add a new Section V: ${ }^{2}$

IV. Members should not participate in live broadcasts of surgical procedures to the general public. The Society believes a possibility exists wherein participating surgeons might fail to follow proper medical procedures or might be distracted because of the media and, thereby, deprive the patient of the highest quality care.

V. Live broadcasts of surgical procedures are not permitted at the Annual Meeting sponsored by The Society.

The AATS Ethics Committee also examined this issue in depth and made three recommendations: the AATS should not adopt the Joint Committee's guidelines, AATS members should not participate in public broadcasts of live surgery, and live broadcasts at national meetings should be prohibited. The council accepted the first two of the committee's recommendations, but directed the AATS Ethics Committee to produce a report addressing the entire spectrum of educational uses of real-time 
cardiothoracic surgery. As the project to develop a broad approach to educational uses of cardiothoracic operations began, The STS was invited to join in the development of the guidelines, and The STS Standards and Ethics Committee was assigned this role.

This report, therefore, is a product of the deliberation on these issues jointly by the AATS and The STS.

\section{The Variety of Conditions for Broadcast Operations}

For purposes of this discussion, we define "live surgery observation" as the viewing of a surgical procedure by third parties in the operating room; "live surgery broadcast" as remote observation of a surgical procedure in real time, using video technology; and "recorded broadcast" as broadcast of a surgical procedure that has been electronically recorded for future local or remote viewing.

Viewing surgery in real time for educational purposes takes place across a spectrum of settings: live surgery observation in the operating room itself; local broadcast of live surgery in or near the operating room; and live surgery broadcasts to sites remote from the operation institution. Recorded procedures, similarly, may be broadcast to a local or remote audience. The size of the audience can range from one or a few individuals to an audience of many thousands. During the procedure, the surgeon may have one-way communication with the audience, describing key technical points, or may have a two-way conversation, accepting comments and answering questions. Operations may be broadcast by closed circuit to a defined audience comprising solely surgeons and other health professionals locally or remotely. An operation may be broadcast to a professional meeting, on an open network accessible to the general public, or on a publicly accessible Web site (eg, or-live.com).

\section{Broadcasts of Live Surgery Compared With Video Recordings}

Surgeons interacting with small groups while operating is a time-honored method of teaching surgical techniques. The risks of incremental harm to patients are probably little different from the risks associated with instruction of residents and medical students during the conduct of operations. Therefore, the remainder of this section will consider only broadcasts of surgical procedures.

Comparisons of live surgery broadcasts with recorded broadcasts are based on assumption, opinion, and anecdotal reports, because, to our knowledge, no objective data exist to support or oppose arguments for or against any form of broadcasting surgical procedures. This discussion, like all discussions of this topic, must be based on published and unpublished observations and opinions.

\section{Positive Aspects}

The positive aspects of broadcasting live or recorded surgical procedures include potential benefits to patients, to the pub- lic, and to surgeons. Patients who agree to participate as subjects of the broadcast operation may gain satisfaction from participating in surgical education, potentially improving surgical outcomes for others in the future.

Public broadcasts may educate lay persons by increasing their understanding of surgery and reassuring some who might require similar operations in the future. To the extent that public broadcasts may be beneficial, live surgery broadcasts may have an advantage over recorded broadcasts because they may draw larger audiences, attracted by the emotional drama associated with live operations.

Similarly, at surgical conferences or on health information networks, closed circuit broadcasts of live surgery, compared with video recordings, may draw larger numbers of surgeons and better hold their attention because of the emotional drama of anticipating unplanned problems and observing how the surgeon solves them, or fails to solve them.

Alternatively, advantages of recorded broadcasts include the opportunity to edit out boring stretches that occur frequently during most operations yet lack educational value. Moreover, the surgeon can add carefully scripted narration of the important points of the operation. Pertinent illustrations may be added to a video recording before broadcast, as can video clips from similar cases that make important teaching points, increasing the instructional power of the recording.

A major advantage of surgical broadcasts to professional groups - one that accrues equally to both live and recorded operations - is the acknowledged educational value of learning operative methods and technical points from experienced master surgeons.

\section{Negative Aspects}

The negative aspects of broadcast surgery include several kinds of potential harm to the patient-subject. Physical injury to the patient-subject during surgical broadcasts has been reported anecdotally, up to and including death. ${ }^{3}$ Assigning blame for such complications to the activities of filming and broadcasting is uncertain, however, insofar as surgical misadventures occur in the absence of broadcasts. Among the factors that may increase the rate of surgical errors during filming is distraction of the surgeon by activities associated with filming. For example, a camera crew in the operating room may seek what they believe to be better vantage points during filming, compromising the surgeon's view. This problem may occur with both live and recorded broadcasts and must be resisted by the surgeon.

The infectious disease literature also documents the increased risk of perioperative infection associated with increasing numbers of people in an operating room, particularly if they are unfamiliar with aseptic technique., ${ }^{4,5}$ Moreover, the likelihood of infection risk rises as a function of time that the incision is open, and unanticipated intraoperative delays related to live broadcasts could occur for many 
reasons, such as synchronous broadcast of different operations at the same time and pauses in the procedure due to distraction of the surgeon.

Certain kinds of distraction occur only during live surgery broadcasts. If the surgeon has direct two-way communication with the audience, discussion about what the surgeon is doing may divert focus from the technical procedure at hand, and this effect can be heightened when an audience member criticizes the surgeon's methods, as has been reported in at least one case. ${ }^{3}$

Surgical judgment may be adversely affected by real-time broadcasts of operations during meetings or over the Internet. Such broadcasts are planned for a specified time frame, which puts pressure on the surgeon to have a patient with the appropriate disease ready for operation at the scheduled time. The patients who are available at that moment, however, may not be the best candidates for the advertised operation. This may produce pressure on the surgeon to do a procedure that would not otherwise have been the first choice, an event that has been reported. Avoidance of embarrassment and time pressure may induce a surgeon to continue an advertised procedure, even if clinical judgment suggests that a different operation would be better, or accept a less satisfactory outcome than would otherwise be tolerated.

In at least one case, the surgeon left the operating room while the patient-subject was still bleeding to converse directly with the audience. ${ }^{6}$ The surgeon might have little or no previous personal experience with a particular device being demonstrated in a session paid for by the manufacturer. Other handicaps and distractions can arise if the surgical broadcasts are from a central site where the surgeon does not work regularly. Examples include unfamiliar staff, equipment, and protocols; difficult communication due to language barriers; and unfamiliarity with local equipment such as echocardiography and x-ray fluoroscopic systems.

Violation of confidentiality of medical information and of the patient-subject's privacy may be threatened by the presence in the operating room of lay persons such as cameramen, directors, and reporters, who are professionals in their own right but may not understand confidentiality at the level of medical professionals. This threat is present for both live and recorded broadcasts, but more so for live broadcasts because some breaches of confidentiality cannot be edited in real time.

The process of informed consent when a patient is asked to be a subject of a surgical broadcast must include full disclosure of potential harms that can result from the extraneous activities associated with video filming. Ensuring that consent to participate in a broadcast is entirely voluntary may be difficult, because many patients do not want to disappoint their surgeons by saying no to their requests. This problem may persist even in the face of reassurance that their surgical care will not be diminished if they decline to participate. In this regard, little difference is apparent between requests to patients to participate in live surgery broadcasts vs recorded broadcasts.
Broadcasts to the public on open Internet or television networks may easily be construed as a misuse of surgical procedures more for entertainment than education. Although such broadcasts may be educationally beneficial, it seems likely that many view them out of a voyeuristic interest in the spectacle of live broadcasts, ${ }^{6}$ similar to those who attend auto races for the possibility of witnessing spectacular crashes. Thus, live surgery broadcasts to the public may serve public prurience rather than public education. This effect is likely to be substantially greater for live surgery broadcasts than for video recordings.

A particularly telling incident regarding the safety of live surgery broadcasts was recounted in a recent description of a meeting of the Japanese Joint Committee, which created the 2007 Japanese live surgery guidelines.

During the committee meeting, when the lawyer member asked the committee as a whole, "Would you all be willing to be the patient in a live surgery session?," all members representing the Societies replied in the negative. At this, the patient representative asked, "In that case, shouldn't live surgery be prohibited?" The prohibition of live surgery was considered, but some agreement was reached on the point that to entirely ignore the educational benefits of live surgery was also surely not to contribute to the future progress of medicine. ${ }^{3}$

Yet, the committee assumed there were educational benefits, neither specifying what they were, nor providing any evidence that they existed at all.

\section{Ethical Considerations}

The prime principle of medical ethics - the core from which other principles are generated-is stated as the first principle in both the AATS Code of Ethics and The STS Code of Ethics, Section 1.1: "When caring for patients, members must hold the patient's welfare paramount". 7,8 This first principle is found in nearly all other codes of medical ethics, including that of the American Medical Association: "A physician shall, while caring for a patient, regard responsibility for the patient as paramount". 9 The Fellowship Pledge in the American College of Surgeon's Statements on Principles, reflects the same idea: "I pledge to pursue the practice of surgery with honesty and place the welfare and the rights of my patients above all else". ${ }^{10}$

In both the AATS Code and The STS Code, this first principle generates a corollary in Section 1.4: "Members should use their best efforts to protect patients from harm by recommending and providing care that maximizes anticipated benefits and minimizes potential harms". ${ }^{11,12}$ The AMA Code has a similar corollary: "Because they are uniquely positioned to have a comprehensive view of the care patients receive, physicians must strive to ensure patient safety and should play an essential role in identifying, reducing, and preventing health care errors". ${ }^{13}$ 
Physicians have an obligation to continue to study and learn throughout their professional lives. This responsibility is made clear in both the AATS Code and The STS Code, Section 5.1: "Members should be actively involved in continuing medical education activities to ensure the continual development of their skills, training, and expertise". ${ }^{14,15} \mathrm{Sec}-$ tion 5.2 continues: "Members should maintain their professional qualities through continuous study consistent with evidence-based scientific practice". ${ }^{16,17}$

Ethical principles may conflict with one another in some situations, and surgery broadcasts engender such a conflict. Surgeons must do what they can to keep their patient-subjects safe and to avoid placing them in harm's way unnecessarily. The obligations to teach and to learn extend to new or unfamiliar techniques and operations, which are exactly what broadcasts of surgical procedures are intended to do. Yet, live surgery broadcasts and recorded broadcasts, to a lesser extent, pose risks to patient-subjects above and beyond those of ordinary operations.

Ethical deliberation often comprises weighing the benefits and harms of one option vs those of another, resulting in choice of the option that provides the highest benefit-to-harm ratio. In the case of surgery broadcasts, relevant data simply do not exist; thus, such objective balancing of benefits and harms is not possible. We do not know how much benefit patients derive from volunteering as patient-subjects, nor do we know how much incremental harm they risk. We also do not know how much educational benefit surgeons derive from viewing live surgery broadcasts compared with viewing video recordings while they are discussed by surgical authorities at meetings or reading journal articles and textbooks describing the same procedure.

We therefore have little choice but to rely on the principles we have espoused in our ethical codes, using our best judgment in weighing the information we have regarding the potential benefits and harms to patient-subjects and benefits to surgical and public education. The gains from live surgical broadcasts to the public seem meager when weighed against potential harms to the patient-subject. Moreover, it is apparent that many public broadcasts on the Internet or on television are intended more as a marketing tool for increasing referrals to the surgeon's own practice rather than as public education. The only constraint on advertising in the AATS Code is a requirement for honesty, expressed in Section 1.9: "In advertising and other publications directed toward patients and the public, members must refrain from making false, deceptive or misleading statements, or other statements not susceptible to verification by the public". ${ }^{18}$ Although marketing a practice by broadcasting operations to the public without deception is not prima facie unethical or illegal, the incremental risks of harm to the patient-subject posed by live surgery broadcasts seem not to be justified.

Certain circumstances could distract surgeons and pressure them into inappropriate decision making in ways that could harm patient-subjects. Such distractions and pressures are likely to be greater with live than with recorded broadcasts, with more rather than fewer time constraints, with two-way communication between audience and surgeon rather than one-way, with operating room personnel who are less familiar with the surgeon's preferences than those in the surgeon's home operating room, and with operating room environments and equipment that are less similar than those that are more similar to the surgeon's home operating room.

On the basis of the factors considered above, cardiothoracic surgeons should follow the following guidelines.

\section{Guidelines for Using the Cardiothoracic Operation as a Teaching Instrument}

1. When planning to record or broadcast an operation, surgeons must pay special attention to the needs and rights of the potential patient-subject.

a. A patient's informed consent for participating as a subject in a live or taped broadcast must be obtained directly by the operating surgeon.

b. The surgeon must disclose the fact of increased risks of harm to the patient and the uncertainty of the degree of such risks, as well as the composition and size of the audience and estimates of the potential educational benefits to participating surgeons.

c. The attending surgeon must take all necessary steps to protect the patient-subject's privacy and to ensure confidentiality of all medical information.

2. Generally, recorded broadcasts, either edited or unedited, are preferable to live surgery broadcasts because recordings intended for later broadcast pose fewer risks of harm to patients.

3. Teaching surgical techniques by live surgery observation in the surgeon's home operating room is a timehonored, acceptable practice.

4. Surgeons should not participate in live surgery broadcasts to the public using any medium, including television and the Internet.

5. National and international cardiothoracic societies should consider prohibiting live surgery broadcasts to large audiences at their annual meetings.

6. Live surgery broadcasts to professional audiences of any size become progressively less acceptable with more rigid scheduling constraints, increasing complexity of the operation, decreasing educational value of the procedure, greater intensity of the surgeon's interaction with the audience, and less familiarity of the surgeon with the operating room environment. On these grounds, live surgery broadcasts are subject to the following conditions:

a. Cardiothoracic surgeons should not participate in live surgery broadcasts when rigid broadcast schedules constrain the operation's starting time or duration or when a specific predetermined operation 
must be fit into a specific time frame. Operations selected for live surgery broadcasts are most acceptable when the operation focuses solely on a particular patient who has a condition that warrants live broadcast.

b. Operations of greater educational value to the surgeons in the audience, relative to their clinical needs, should be chosen over operations of lesser educational value. Operations are inappropriate for live broadcast if intended to show that an operation can be done rather to demonstrate to others how to do it.

c. Cardiothoracic surgeons should not participate in broadcasts of operations that have a major purpose of aggrandizement of the surgeon or of the surgeon's operating facility.

d. The operating surgeon should be thoroughly familiar with and experienced in the procedure being broadcast and with the specific medical devices and tools being demonstrated. Innovative operations and rare procedures that the surgeon has never or only occasionally performed previously should not be broadcast because they lack educational value and increase the need for the surgeon's undivided attention.

e. Whenever possible, surgery should be broadcast from the surgeon's home operating room. When this is not possible, the operative facility should be configured as closely as possible to the surgeon's home operating room environment. Only highly experienced operating room staff who are fluent in the surgeon's preferred language should participate, preferably the surgeon's own staff. The surgeon must ensure that the video crew does not interfere with the progress of the operation, whether filming is intended for live or recorded broadcast.

f. Because discussion with a remote audience during an operation may distract the surgeon, discussions should be one-way, from surgeon to audience. If a two-way discussion is demonstrably essential to the educational value, questions and comments from the audience should be controlled, for example, relayed through a moderator who alone can communicate with the surgeon.

g. Cardiothoracic surgeons should not participate in any capacity in live surgery programs that violate these guidelines.

h. The operating surgeon has a responsibility to ensure completion of the following requirements before each broadcast:

i. The operating facility, if not in the surgeon's home institution, should be suitable for the conduct of the operation to be broadcast. ii. A preoperative conference should be held with the principal parties, including the operating surgeon and key medical and technical (filming) staff, to review the ethical guidelines and safety standards under which the operation will be performed.

iii. A reliable mechanism should be in place for the audience to receive follow-up reports on the outcome of the operation within 24 hours and the status of the patient 30 days after the broadcast.

7. Violation of these guidelines may lead to disciplinary action by Association/Society.

\section{References}

1. Misaki T, Takamoto S, Matsuda H, et al. Guidelines to live presentations of thoracic and cardiovascular surgery. Available at http://square. umin.ac.jp/jscvs/eng/live.html. Accessed May 11, 2008.

2. The Society of Thoracic Surgeons. Guidelines for ethical relations with communications media. Available at http://www.sts.org/ sections/aboutthesociety/policies/Ethical\%20Relations. Accessed May $11,2008$.

3. Takamoto S. Guidelines for live surgery. CTSNet, October 19, 2007. Available at http://www.ctsnet.org/sections/newsandviews/inmyopinion/ articles/article-63.html. Accessed May 11, 2008.

4. Bethune DW, Blowers R, Parker M, Pask EA. Dispersal of Staphylococcus aureus by patients and surgical staff. Lancet. 1965;1:480-3.

5. Pryor F, Messmer PR. The effect of traffic patterns in the OR on surgical site infections. AORN J. 1998;68:649-60.

6. Cameron DE. Surgery as spectacle. CTSNet, September 6, 2005. Available at http://www.ctsnet.org/sections/newsandviews/inmyopinion/ articles/article-55.html. Accessed May 11, 2008.

7. American Association for Thoracic Surgery. Code of ethics, section 1.1. Available at http://www.aats.org. Accessed June 11, 2008.

8. The Society of Thoracic Surgeons. Code of ethics section 1.1. Available at http://www.sts.org/sections/aboutthesociety/policies/code \%20of\%20ethics/. Accessed May 11, 2008.

9. American Medical Association. Principles of medical ethics. Code of medical ethics of the American Medical Association. 2006-2007 ed. Chicago, IL: American Medical Association; 2006: xv.

10. American College of Surgeons. Fellowship pledge, statements on principles. Available at http://www.facs.org/fellows_info/statements/ stonprin.html\#fp. Accessed May 11, 2008.

11. American Association for Thoracic Surgery. Code of ethics, section 1.4. Available at http://www.aats.org. Accessed June 11, 2008.

12. The Society of Thoracic Surgeons. Code of ethics section 1.4. Available at http://www.sts.org/sections/aboutthesociety/policies/code\% 20of\%20ethics/. Accessed May 11, 2008.

13. American Medical Association. Ethical opinion E-8.121 Ethical responsibility to study and prevent error and harm. Code of medical ethics of the American Medical Association. 2006-2007 ed. Chicago, IL: American Medical Association; 2006: 242-3.

14. American Association for Thoracic Surgery. Code of ethics, section 5.1. Available at http://www.aats.org. Accessed June 11, 2008.

15. The Society of Thoracic Surgeons. Code of ethics section 5.1 Available at http://www.sts.org/sections/aboutthesociety/policies/code\%20of\%20 ethics/. Accessed May 11, 2008.

16. American Association for Thoracic Surgery. Code of ethics, section 5.2. Available at http://www.aats.org. Accessed June 11, 2008.

17. Code of ethics section 5.2. Available at http://www.sts.org/sections/ aboutthesociety/policies/code\%20of\%20ethics/. Accessed May 11, 2008.

18. American Association for Thoracic Surgery. Code of ethics, section 1.9. Available at http://www.aats.org. Accessed June 11, 2008. 